\title{
THE EFFECT OF MERCURIAL DIURETICS ON RENAL AMMONIA AND TITRATABLE ACIDITY PRODUCTION IN ACIDOTIC HUMAN SUBJECTS WITH REFERENCE TO SITE OF DIURETIC ACTION ${ }^{1}$
}

\author{
BY RAYMOND E. WESTON, JACOB GROSSMAN, AND LOUIS LEITER
}

(From the Medical Division, Montefiore Hospital, New York City)

(Submitted for publication June 30, 1951; accepted August 13, 1951)

Experimental analysis of renal regulation of sodium and chloride excretion is complicated by the fact that the functional contributions of the proximal and the distal tubular segments to the urinary electrolyte pattern cannot be readily separated. If electrolyte transport in one of these tubular sites could be significantly depressed without affecting the other, it might be possible to clarify this tubular division of labor, particularly with regard to the suggested relationship between variations in glomerular filtration rate and electrolyte excretion $(1,2)$.

The mercurial diuretics, which reversibly inhibit tubular reabsorption of electrolytes and water, would be valuable tools for such a dissection of tubular function if it could be established that such inhibition is localized to a particular tubular segment. However, the precise renal locus of this action of mercurials has not been unequivocally demonstrated (3).

In dogs, following the minimal doses of mercury which produce anatomic changes, microscopic lesions are seen only in the cells of the proximal tubule. Therefore, organic mercurials may be expected to interfere significantly with proximal tubular function (4). This surmise is supported by reports that certain presumptively proximal tubular functions, such as the secretion of diodrast and para-aminohippurate and the reabsorption of glucose, uric acid and calcium, are significantly depressed in man by therapeutic doses of mercurial diuretics (5-9).

However, in the dog secretion of para-aminohippurate is not affected by diuretic doses of salyrgan (6). Moreover, renal aniso-osmotic reabsorption of water and electrolytes, which requires the major energy expenditure in electrolyte and

\footnotetext{
1 Supported in part by grants from the National Heart Institute, U. S. Public Health Service, Campbell Pharmaceutical Co., and the Martha M. Hall Foundation.
}

water excretion, probably takes place in the distal tubule $(1,10)$. While it seems unlikely that a toxic heavy metal such as mercury would fail to affect the distal tubular enzyme systems involved in this process, no direct evidence has been presented as yet that mercurials in the usual therapeutic doses produce any anatomical or functional changes in the distal tubules. Therefore, the present investigation was undertaken to study in human subjects the effect of organic mercurials on the only active renal functions specifically attributed to the distal tubule : namely, ammonia and titratable acidity production (11). The significance of the data obtained is discussed in relation to the site of action of mercurial diuretics.

\section{METHODS AND MATERIALS}

The subjects of this investigation included eight patients in congestive failure who were maintained on a low salt cardiac diet and two patients without heart disease on a regular hospital diet. Acidosis was produced by the administration of 9 to 12 grams of ammonium chloride (Enseals ${ }^{2}$ ) daily in divided doses for three to five days. Then, with the patient resting in the postabsorptive state, a soft-rubber multi-holed vesical catheter was inserted and urines collected under mineral oil during moderate water diuresis. Bladder emptying at the end of each period was promoted by suprapubic pressure alone without the usual bladder washout technique. The constancy of the urinary electrolyte, ammonia and titratable acidity excretion during the three to five $\mathbf{1 5}$ to 20 minute control periods indicates that adequate bladder emptying was achieved. After the intravenous administration of $2 \mathrm{ml}$. of either Mercuzanthin or Thiomerin, urine collections were continued until some time after maximal diuretic effect had been attained. In all cases, urines were analyzed immediately for ammonia, $\mathrm{pH}$ and titratable acidity, later, for chloride and in some instances also for phosphate, sodium, potassium and calcium. Additional experimental details and variations in experimental design are discussed below.

In two acidotic patients (R. W. and H. M.) simultane-

\footnotetext{
2 Supplied by Eli Lilly and Co.
} 
ous measurements of inulin and PAH clearances, blood and urine electrolytes, and urinary $\mathrm{pH}$, ammonia and titratable acidity during control periods and during buffered phosphate infusions, before and after the administration of the mercurial, were also carried out. The same procedures were repeated in one patient (A. C.) before and during an infusion of $2.5 \%$ sodium chloride. Then, $2 \mathrm{ml}$. of Thiomerin were injected intravenously and the infusion continued at the same rate.

Urine and serum or plasma analyses were performed as follows: Ammonia by the method of Van Slyke and Cullen (12) ; titratable acidity by the method of Henderson and Palmer (13); phosphate by the method of Fiske and Subbarow (14); chloride by the modification of Sendroy's iodometric method by Van Slyke and Hiller (15) ; sodium and potassium by means of a lithium internal standard flame photometer; calcium by the methods of Clark and Collip (16) and Fiske and Logan (17); inulin and PAH as modified by the NYU-Bellevue group (18) ; and $\mathrm{pH}$ with a Beckman $\mathrm{pH}$ meter.

\section{RESULTS}

\section{A. Effect of mercurial diuretics on urinary am- monia and titratable acidity}

Figure 1 presents the results of a control experiment which demonstrates that in an acidotic subject, when no mercurial diuretic was administered, no significant change in urinary chloride, ammonia or titratable acidity excretion occurred during approximately four hours.

In Table $I$ are presented the data on urinary water, chloride, ammonia and titratable acidity of eight patients during the control periods and at the peak of water and electrolyte diuresis after administration of a mercurial. It is evident that ammonia excretion was unaffected by the mercurial in six patients and decreased slightly in two.
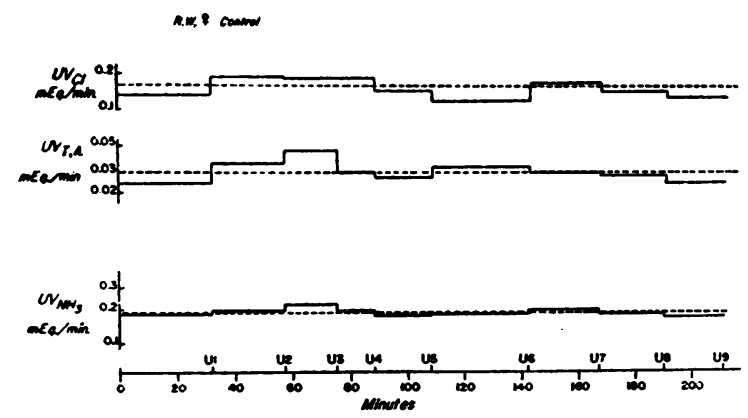

Fig. 1. Control Experiment Demonstrating the Constancy of Urinary Excretion of Ammonia, Titratable Acidity, and Chloride in an Acidotic Subject in the Absence of a Mercurial Diuretic

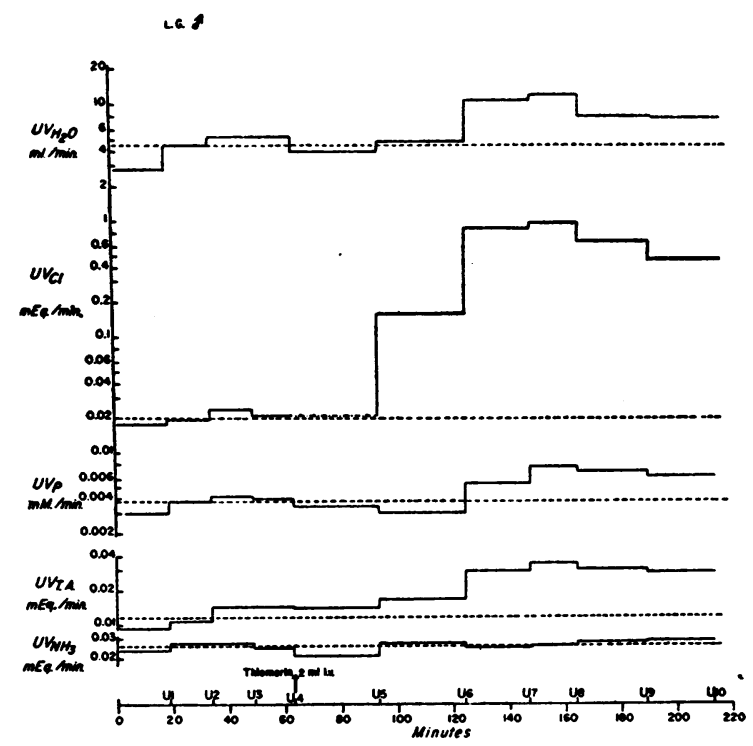

Fig. 2. Parallel Increase in Urinary Excretions of Phosphate and Titratable Acid during Mercurial DiURESIS

Note that ammonia excretion is unchanged.

In contrast, titratable acidity significantly increased in all coincidentally with the diuresis following administration of the mercurial. The actual increases ranged from $26 \%$ to $164 \%$ (mean $=87 \%$ ).

That mercury, a general protoplasmic poison, should increase distal tubular excretion of titratable acidity seemed paradoxical. However, as Pitts and his coworkers have demonstrated in dogs (19) and man (20), renal production of titratable acidity is a direct function of the amount of buffer delivered to the distal tubular segments. Therefore, it appeared possible that the increased urinary titratable acidity during diuresis in acidotic subjects might reflect a mercurial inhibition of proximal tubular reabsorption of phosphate or bicarbonate, which would increase the amount of buffer available to the distal tubules.

To test this hypothesis, urinary phosphorus excretion was also measured during control periods and following mercurial administration to four of the patients (Table I). In the three who exhibited significant increases in urinary titratable acidity after the mercurial, there was coincidental enhancement of phosphorus excretion (Figure 2).

Prior to giving the mercurial, the load of phosphate and other buffer delivered to the distal seg- 
TABLE I

Urinary excretion of ammonia, titratable acidity, chloride, phosphate and $p H$ in acidotic subjects before and during maximal mercurial diuresis

\begin{tabular}{|c|c|c|c|c|c|c|c|c|c|c|c|c|}
\hline \multirow{2}{*}{ Patient } & \multicolumn{2}{|c|}{ Volume } & \multicolumn{2}{|c|}{ Chloride } & \multicolumn{2}{|c|}{ Ammonia } & \multicolumn{2}{|c|}{ Titr. acid } & \multicolumn{2}{|c|}{ Phosphate } & \multicolumn{2}{|c|}{$\mathrm{pH}$} \\
\hline & Control & Hg max. & Control & Hg max. & Control & Hg max. & Control & Hg max. & Control & Hg max. & Control & Hg max. \\
\hline $\begin{array}{l}\text { B. A. } \\
\text { C. R. } \\
\text { J. P. } \\
\text { R. W. } \\
\text { E. B. } \\
\text { B. S. } \\
\text { L. G. } \\
\text { A. P. }\end{array}$ & $\begin{array}{c}\text { ml./min. } \\
0.85 \\
7.16 \\
8.00 \\
6.23 \\
2.83 \\
4.84 \\
4.46 \\
9.14\end{array}$ & $\begin{array}{c}\text { ml./min. } \\
4.50 \\
17.1 \\
27.3 \\
26.3 \\
6.80 \\
16.1 \\
11.7 \\
22.6\end{array}$ & $\begin{array}{l}m E q . / \min . \\
.0886 \\
.163 \\
.568 \\
.411 \\
.0584 \\
.482 \\
.0198 \\
.318\end{array}$ & $\begin{array}{c}\text { mEq./min. } \\
.637 \\
1.99 \\
3.06 \\
3.21 \\
.666 \\
1.28 \\
.944 \\
2.92\end{array}$ & $\begin{array}{l}m E q . / \min . \\
.0542 \\
.0736 \\
.123 \\
.186 \\
.0717 \\
.118 \\
.0241 \\
.132\end{array}$ & $\begin{array}{l}m E q . / \min . \\
.0648 \\
.0766 \\
.0956 \\
.156 \\
.0765 \\
.107 \\
.0272 \\
.126\end{array}$ & \begin{tabular}{|c|}
$m E q . / \min$. \\
0.0151 \\
0.0256 \\
0.0481 \\
0.0288 \\
0.0115 \\
0.0342 \\
0.0116 \\
0.0251
\end{tabular} & $\begin{array}{c}m E q . / \min . \\
0.0314 \\
0.0458 \\
0.0669 \\
0.0638 \\
0.0387 \\
0.0434 \\
0.0322 \\
0.0459\end{array}$ & $\begin{array}{l}.00752 \\
.0193 \\
.00365 \\
.0047\end{array}$ & $\begin{array}{l}.0142 \\
.0160 \\
.00732 \\
.0116\end{array}$ & $\begin{array}{l}5.8 \\
4.8 \\
6.0\end{array}$ & $\begin{array}{l}4.2 \\
4.7 \\
4.6\end{array}$ \\
\hline
\end{tabular}

ments was so small that urinary titratable acidity was only $5 \%$ to $10 \%$ of the values observed in acidotic men during phosphate infusions (20). With the increase in distal tubular buffer load following the mercurial, production of titratable acidity doubled but still did not exceed $10 \%$ to $30 \%$ of that observed during phosphate administration. This suggested that the previous failure to detect any inhibition of titratable acidity production after a mercurial may have been due to experimental conditions which did not provide a buffer load sufficient to strain this distal tubular function. Under these circumstances, if titratable acidity production were only partially depressed by mercurials, a small decrease might be masked by the greater increase secondary to the larger quantity of buffer escaping proximal reabsorption. Therefore, to determine whether mercurials do depress this function, titratable acidity production should be first maintained at a high level by providing not only an acidotic stimulus ${ }^{\circ}$ but also a greater buffer load prior to administration of the

TABLE II

Urinary excretion of ammonia, titratable acid and electrolytes in acidotic subject $(R$. W.) during continuous infusion of isotonic sodium phosphate solution before and after administration of a mercurial

\begin{tabular}{|c|c|c|c|c|c|c|c|c|c|c|c|c|}
\hline \multirow{2}{*}{ Remarks } & \multirow{2}{*}{ Period } & \multirow{2}{*}{$\begin{array}{c}\text { Elapsed } \\
\text { time }\end{array}$} & \multirow{2}{*}{ G.F.R. } & \multirow{2}{*}{$\begin{array}{l}\text { Urine } \\
\text { flow }\end{array}$} & \multirow{2}{*}{$\begin{array}{l}\text { Urine } \\
\mathrm{NH}_{2}\end{array}$} & \multirow{2}{*}{$\begin{array}{l}\text { Titr. } \\
\text { acid. }\end{array}$} & \multicolumn{3}{|c|}{ Urinary electrolytes } & \multicolumn{3}{|c|}{ Serum electrolytes } \\
\hline & & & & & & & Phosphate & Sodium & Chloride & Phosphate & Sodium & Chloride \\
\hline Control & $\begin{array}{l}1 \\
2 \\
3\end{array}$ & $\begin{array}{l}\min . \\
15 \frac{1}{2} \\
26 \frac{1}{2} \\
43\end{array}$ & $\begin{array}{c}\text { ml./min. } \\
116 \\
111 \\
116\end{array}$ & $\begin{array}{c}\text { ml./min. } \\
8.78 \\
12.0 \\
12.7\end{array}$ & $\begin{array}{c}m E q . / \min . \\
0.194 \\
0.180 \\
0.178\end{array}$ & $\begin{array}{c}\text { mEq./min. } \\
.0272 \\
.0247 \\
.0273\end{array}$ & $\begin{array}{l}m M / \min . \\
.00790 \\
.0104 \\
.00790\end{array}$ & $\begin{array}{c}m E q . / m i n . \\
0.103 \\
0.096 \\
0.086\end{array}$ & $\begin{array}{c}m E q . / m i n \\
0.238 \\
0.239 \\
0.222\end{array}$ & $\begin{array}{c}m M / l \\
0.89 \\
0.80\end{array}$ & $\begin{array}{c}m E q \cdot / l \\
139 \\
138\end{array}$ & $\begin{array}{c}m E q . / l \\
111 \\
111\end{array}$ \\
\hline $\begin{array}{l}\text { Sodium } \\
\text { phosphate } \\
\text { infusion* }\end{array}$ & $\begin{array}{r}4 \\
5 \\
6 \\
7 \\
8 \\
9 \\
10 \\
11 \\
12\end{array}$ & $\begin{array}{c}70 \\
97 \\
122 \\
149 \\
163 \frac{1}{2} \\
197 \frac{1}{2} \\
229 \frac{1}{2} \\
245 \frac{1}{2} \\
261\end{array}$ & $\begin{array}{r}119 \\
116 \\
91 \\
124 \\
106 \\
100 \\
123 \\
123 \\
118\end{array}$ & $\begin{array}{c}6.44 \\
7.19 \\
4.40 \\
3.71 \\
6.76 \\
1.47 \\
3.88 \\
10.0 \\
9.94\end{array}$ & $\begin{array}{l}0.294 \\
0.180 \\
0.164 \\
0.171 \\
0.169 \\
0.137 \\
0.190 \\
0.168 \\
0.156\end{array}$ & $\begin{array}{l}.0792 \\
.0771 \\
.0426 \\
.0906 \\
.0810 \\
.0764 \\
.143 \\
.140 \\
.131\end{array}$ & $\begin{array}{l}.0136 \\
.0360 \\
.0272 \\
.0596 \\
.0906 \\
.0750 \\
.107 \\
.129 \\
.119\end{array}$ & $\begin{array}{l}0.075 \\
0.061 \\
0.037 \\
0.063 \\
0.066 \\
0.066 \\
0.095 \\
0.128 \\
0.125\end{array}$ & $\begin{array}{l}0.212 \\
0.158 \\
0.079 \\
0.117 \\
0.092 \\
0.079 \\
0.081 \\
0.078 \\
0.066\end{array}$ & $\begin{array}{l}1.22 \\
1.25 \\
1.47 \\
1.55 \\
1.75 \\
1.75 \\
2.02 \\
2.16 \\
2.38\end{array}$ & $\begin{array}{l}141 \\
140 \\
142 \\
139 \\
141\end{array}$ & $\begin{array}{l}110 \\
109 \\
110 \\
109 \\
109 \\
109 \\
107 \\
106 \\
106\end{array}$ \\
\hline $\begin{array}{l}2 \text { ml. Thio- } \\
\text { merin I.V. }\end{array}$ & $\begin{array}{l}13 \\
14 \\
15 \\
16 \\
17 \\
18 \\
19\end{array}$ & $\begin{array}{l}281 \frac{1}{2} \\
297 \frac{1}{2} \\
312 \frac{1}{2} \\
321 \frac{3}{4} \\
330 \frac{1}{2} \\
351 \frac{1}{2} \\
395 \frac{1}{2}\end{array}$ & $\begin{array}{r}72 \\
93 \\
130 \\
120 \\
108 \\
105 \\
101\end{array}$ & $\begin{array}{c}4.10 \\
1.19 \\
15.2 \\
27.1 \\
24.5 \\
16.1 \\
9.86\end{array}$ & $\begin{array}{c}0.128 \\
-\overline{185} \\
0.157 \\
0.149 \\
0.146 \\
0.142\end{array}$ & $\begin{array}{l}.103 \\
.137 \\
.228 \\
.249 \\
.234 \\
.245 \\
.221\end{array}$ & $\begin{array}{l}.0860 \\
.117 \\
.190 \\
.196 \\
.209 \\
.184 \\
.165\end{array}$ & $\begin{array}{l}0.095 \\
1.45 \\
2.70 \\
2.63 \\
2.06 \\
1.36\end{array}$ & $\begin{array}{l}0.050 \\
0.060 \\
1.49 \\
2.82 \\
2.62 \\
1.80 \\
1.37\end{array}$ & $\begin{array}{l}2.54 \\
2.82 \\
2.76\end{array}$ & $\begin{array}{l}141 \\
142\end{array}$ & $\begin{array}{r}104 \\
100 \\
99\end{array}$ \\
\hline
\end{tabular}

* Isotonic solution at $\mathrm{pH}=7.3$, administered at a rate of $3.5 \mathrm{ml} . / \mathrm{min}$. from periods 4 to 9 , and of $5 \mathrm{ml} . / \mathrm{min}$. from periods 9 through 19. 


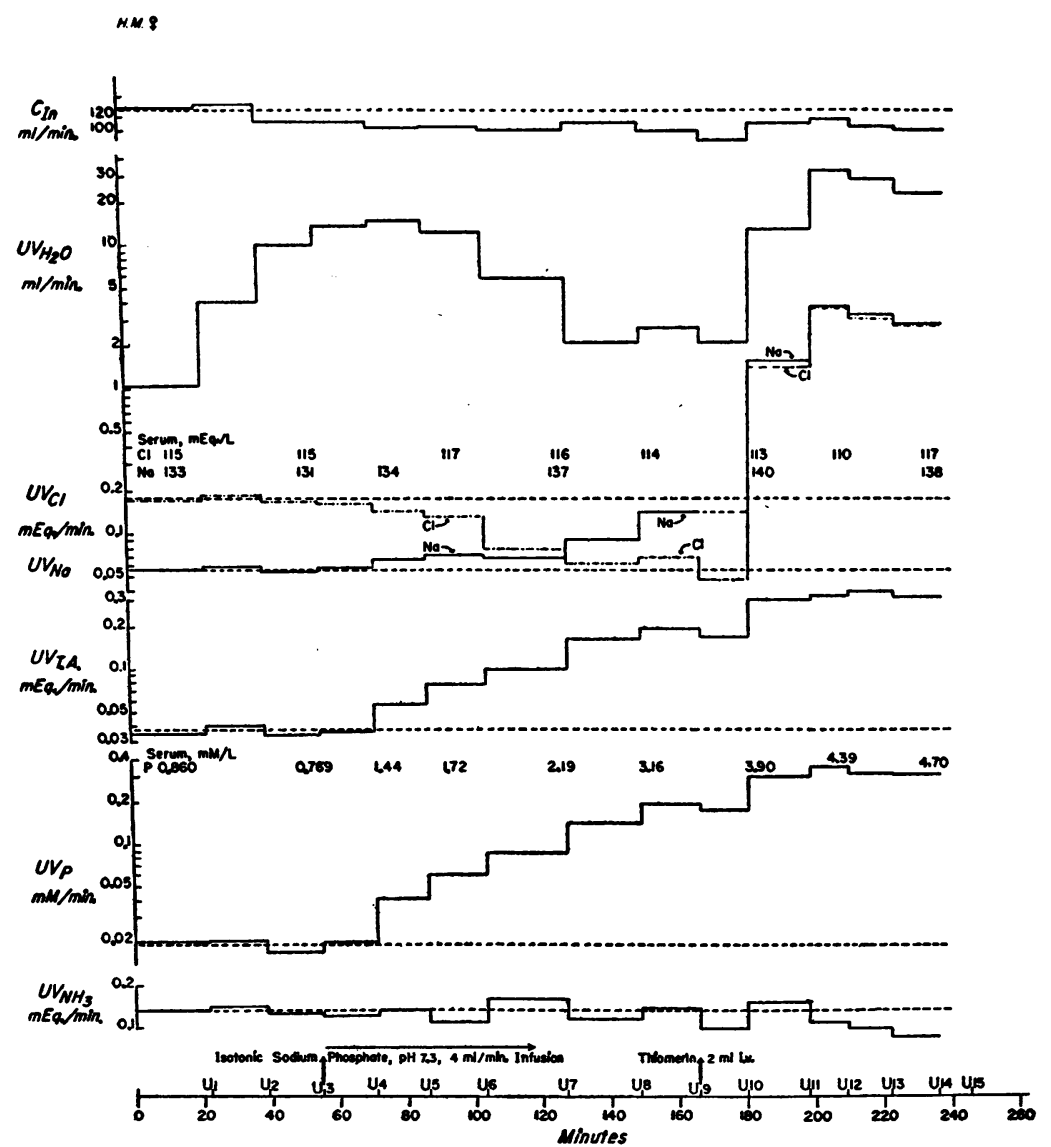

Fig. 3. Parallel Increase in Urinary Excretion of Phosphate and Titratable Acid during a Phosphate Infusion prior to and following the Administration of Thiomerin

mercurial. This was attempted in the experiments presented below.

\section{B. Effect of mercurial diuretics on urinary $p H$, ammonia, titratable acidity and electrolyte excretion during sodium phosphate infusion}

In two fasting patients (H. M. and R. W.) previously maintained on 9 to 12 grams of ammonium chloride per day for four days, simultaneous measurements of inulin, $\mathrm{PAH}$, and electrolyte clearances, and of urinary $\mathrm{pH}$, ammonia, and titratable acidity were performed for three or four control periods, during infusions of an isotonic sodium phosphate solution buffered to $\mathrm{pH}=7.3$ at a rate of $4 \mathrm{ml} . / \mathrm{min}$. for 100 and 240 minutes, respectively, before administering the mercurial, and continued until after maximal diuresis had been achieved. Urine was collected under oil as described above.

As Table II and Figure 3 illustrate, during the phosphate infusion, with the greater distal load of buffer reflected by the higher urinary phosphate excretion, there was a progressive increase in titratable acidity. As before, after the mercurial, the titratable acidity production increased in both cases as the urinary phosphate excretion was augmented. Figures 4 and 5 illustrate the direct relationship between phosphate and titratable acidity excretion before and after the mercurial.

\section{The effect of a concentrated sodium chloride infusion on urinary ammonia, titratable acidity and electrolyte excretion before and after a mercurial}

Renal ammonia secretion also may involve an ion exchange reaction in which ammonia replaces 
tubular sodium. It is conceivable that the increased distal sodium load after mercurial inhibition of proximal reabsorption might enhance ammonia secretion in these acidotic subjects, thereby masking any partial mercurial depression of this distal function. In fact, Ryberg (21) has reported that in acidotic human subjects, oral administration of concentrated salt solutions did result in such an increased urinary ammonia production, as the urinary sodium excretion increased.

Therefore, in an acidotic male (A. C.) with normal kidneys, clearances of inulin and electrolytes, including calcium, and urinary ammonia, titratable acidity and $\mathrm{pH}$ were measured during four control periods, and during infusion of a $2 \frac{1}{2} \%$ sodium chloride solution at a rate of $8 \mathrm{ml} . / \mathrm{min}$. for 90 minutes. Then, $2 \mathrm{ml}$. of Thiomerin were injected intravenously and the infusion of the concentrated salt solution was continued at the same rate as before. Sixty minutes later, when the urine volume began to fall from its post-mercurial maximum, 0.5 gram of aminophyllin was slowly injected intravenously, in an effort to increase filtration rate and to determine the maximal diuretic effect obtainable under these conditions (Table III and Figure 6).

At the start of the concentrated salt infusion, after a transient decrease, the rates of urinary potassium, phosphate, ammonia and titratable acidity

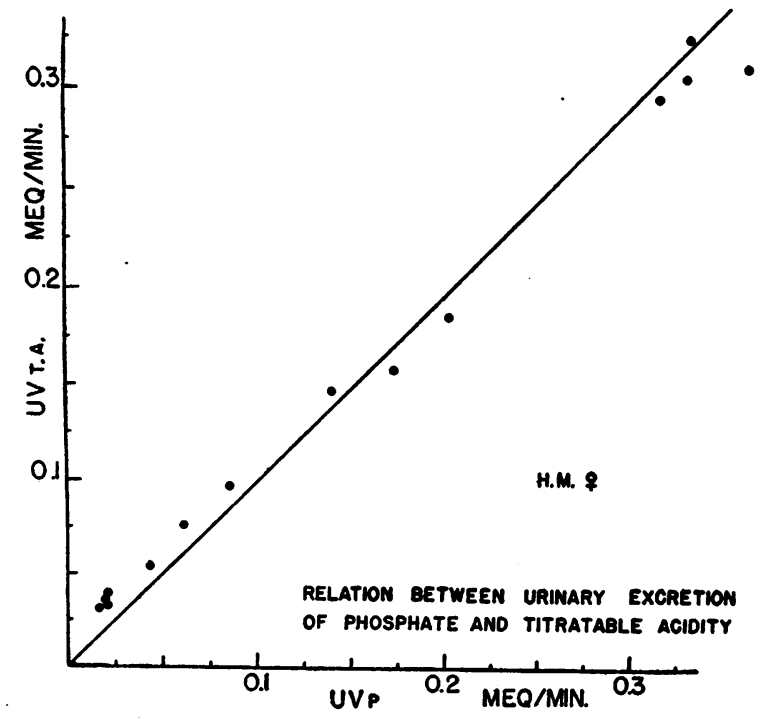

Fig. 4. Relationship between Phosphate and Titratable Acidity Excretion during a Phosphate InFusion aNd AFTer a Mercurial DiURetic

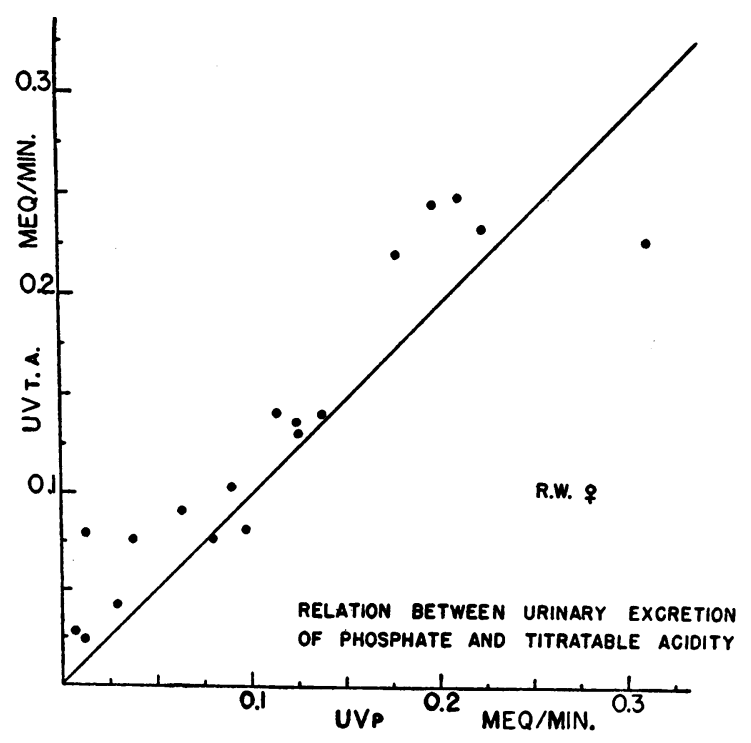

Fig. 5. Relationship between Phosphate and TItratable Acidity Excretion during a Phosphate InFusion aNd AFter a Mercurial DiURetic

excretion returned to control levels, but urinary volume remained low. Simultaneously, the excretions of sodium, chloride and calcium and the glomerular filtration rate increased to above control levels; the rise in the latter, however, was more gradual and continued even after the mercurial was given. ${ }^{3}$ Thus, despite the increased sodium load delivered to the distal tubules, there was no significant potentiation of ammonia production.

After administration of the mercurial, despite the rapid onset of profuse water, sodium and chloride diuresis, and a marked increase in calcium, potassium and phosphate excretion, there was no significant change in ammonia production; titratable acidity production doubled. At peak diuresis $\left(\mathrm{U}_{11}\right)$, urine volume was $42.2 \mathrm{ml} . / \mathrm{min}$. or $32.9 \%$ of the filtration rate, sodium excretion was 6.25 $\mathrm{mEq} . / \mathrm{min}$., or $33.8 \%$ of that filtered, and chloride excretion was $6.80 \mathrm{mEq} . / \mathrm{min}$. or $38.8 \%$ of that filtered. Calcium excretion was $2.41 \mathrm{mgm} . / \mathrm{min}$. When aminophyllin was given, filtration rate increased significantly. Simultaneously, there was an increase in urine volume to $43.9 \mathrm{ml} . / \mathrm{min}$. ( $31 \%$ of the GFR), in urinary sodium excretion to $34.1 \%$ of the filtered sodium, in chloride excretion to $39.2 \%$ of the filtered chloride. During the next

\footnotetext{
3 The continued increase in glomerular filtration cannot be attributed to the Thiomerin, a non-xanthine containing mercurial.
} 
MERCURIAL DIURETICS AND URINARY ACIDITY

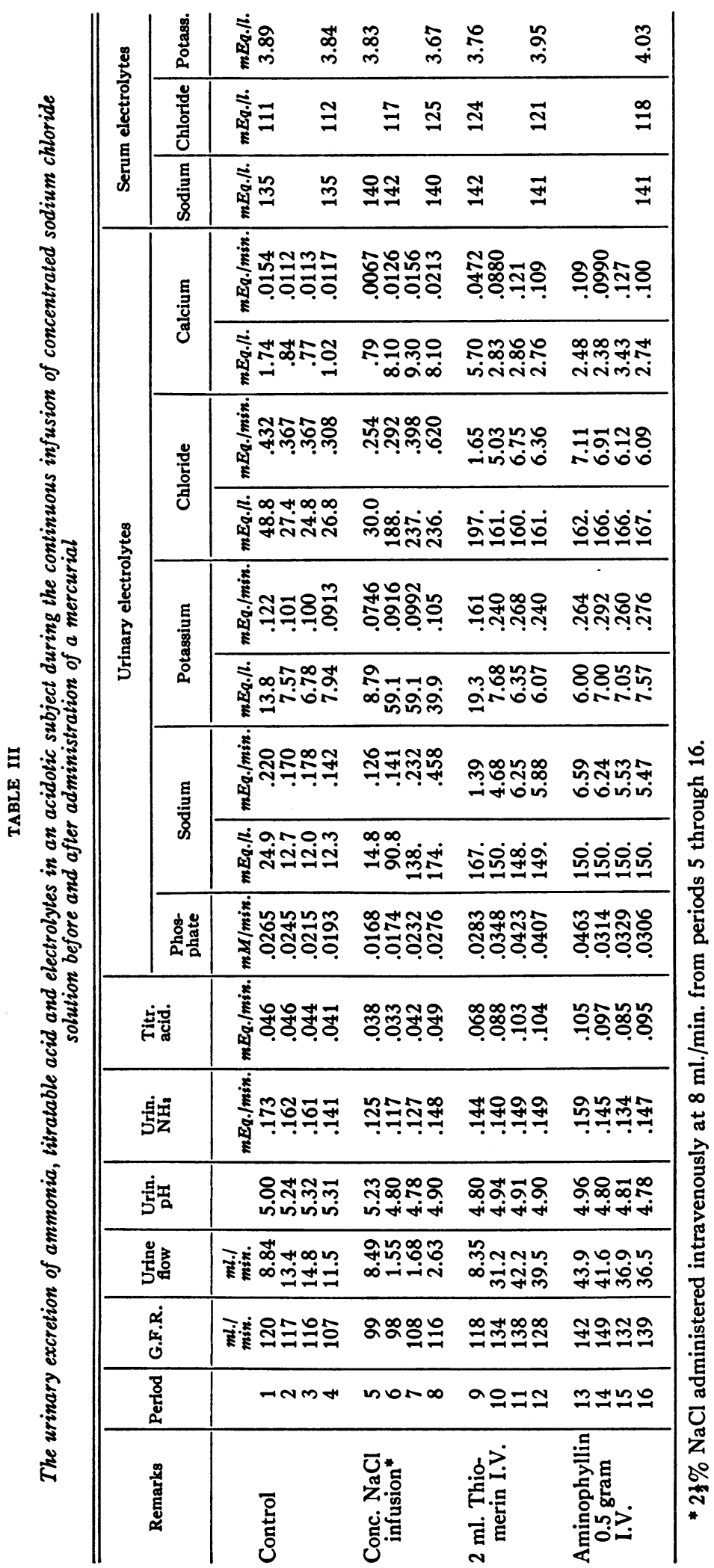



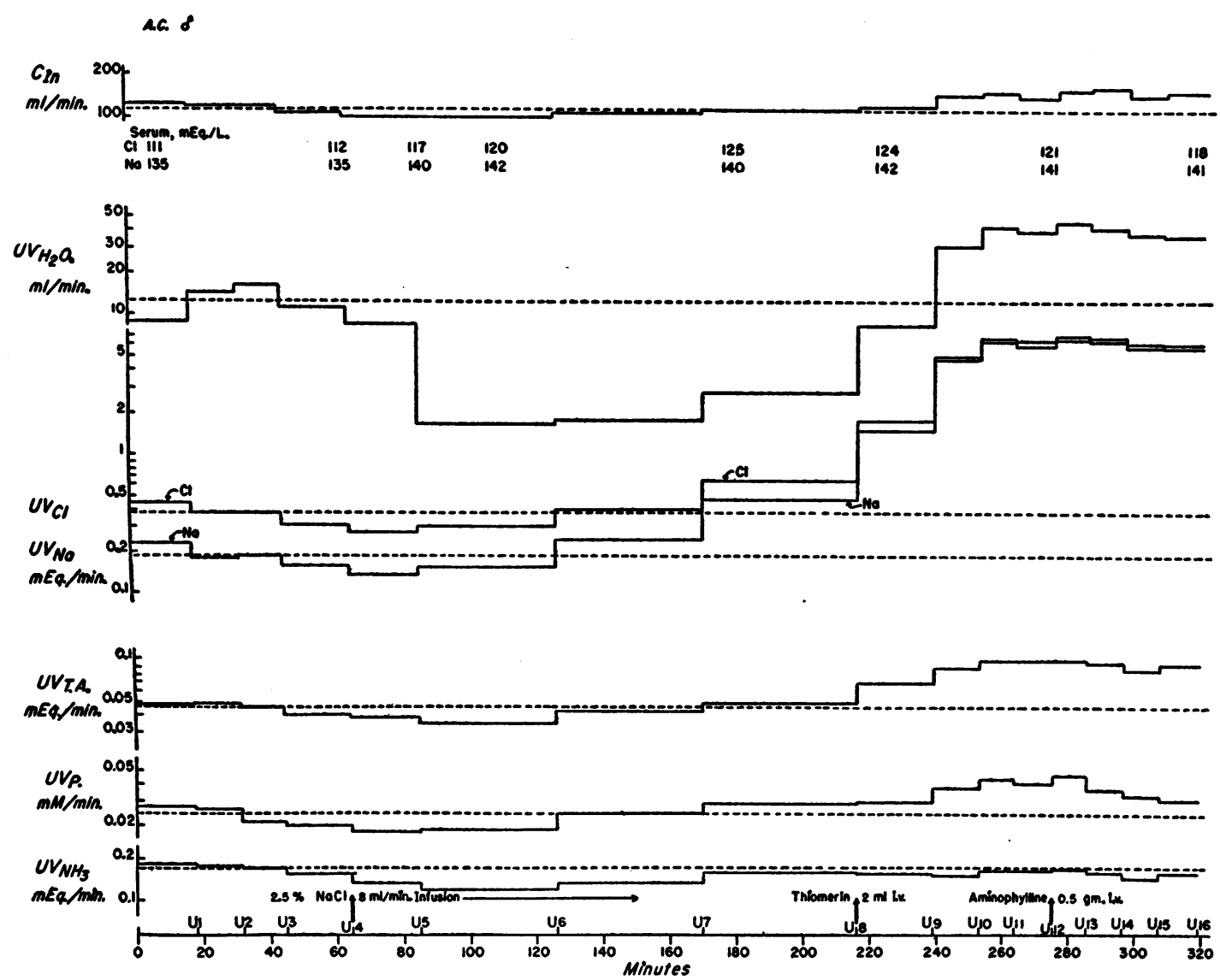

Fig. 6. Urinary Excretion of Ammonia, Titratable Acidity, and Electrolytes during a Concentrated Sodium Chloride Infusion prior to and following the Administration of a Mercurial DiURETIC

three periods as the filtration rate decreased somewhat and the effect of the mercurial waned, urinary volume and sodium, chloride, phosphate, titratable acidity, and calcium excretion fell without a significant change in ammonia production.

Potassium excretion also was maximal during $\mathrm{U}_{11}$, reached a new peak during $\mathrm{U}_{13}$ after aminophyllin, and remained high. The maximal potassium clearance achieved was $69.5 \mathrm{ml} . / \mathrm{min}$. at which time the $C_{K} / C_{I n}$ ratio was 0.46 .

\section{DISCUSSION}

The demonstration that in ammonium chloride acidosis mercurial diuretics do not reduce ammonia production and may actually increase titratable acidity production has a number of interesting implications. The potentiation of mercurial action by pretreatment with acidifying salts is not clearly understood (3). One explanation may follow from the fact that in acidosis the base-conserving mechanisms of the distal tubule normally function at high levels. If mercurials were to inhibit ammonia and titratable acidity production, diuresis would be increased by the excretion of the additional sodium ordinarily retained by these cation exchange processes. Such potentiation of mercurial action by acidosis would then suggest that the distal tubule is a locus of mercurial diuretic action. Since these mechanisms are not depressed by mercury, acidotic enhancement of mercurial diuresis must depend upon some other process.

The fact that these two distal tubular functions are not depressed by mercurials does not exclude the action of these drugs on other distal tubular mechanisms for reabsorbing electrolytes and water. 
However, the increased titratable acidity, paralleling the increased phosphate excretion after mercurials, provides evidence that this distal tubular function is unimpaired when the proximal tubular mechanism for reabsorbing phosphate is depressed by mercury.

A number of other presumably proximal tubular functions-diodrast and para-aminohippurate secretion, and glucose, uric acid, calcium and potassium reabsorption-are known to be depressed by mercurial diuretics in man $(5-9,22)$. With such widespread inhibition of other proximal functions, it seems improbable that sodium and chloride reabsorption by the proximal tubule would be spared.

When the present investigations of the mechanism of mercurial action were begun, it was generally held that the proximal reabsorption of sodium was iso-osmotic (10), and theoretically involved little expenditure of energy. Therefore, in seeking the functional segment where mercury could interfere with energy expanding processes and produce diuresis, attention was focused on the distal tubule, in which reabsorption of water and electrolyte is aniso-osmotic and, therefore, active. Since then, others $(23,24)$ have presented evidence suggesting that part, at least, of proximal tubular sodium and chloride reabsorption may be an active process. In view of this, a mercurial inhibitory effect on this activity which involves osmotic work must be considered.

Whether mercurials have a significant effect on distal tubular reabsorption of sodium, chloride or water remains to be established. Several investigators have concluded that mercurials fail to affect Pitressin antidiuresis since Pitressin diminishes the water diuresis following mercurials, without decreasing the electrolyte diuresis $(3,25)$. Since facultative water reabsorption, which concentrates the urine with respect to electrolytes during Pitressin antidiuresis, is presumably localized to the distal tubular segments, this may be another distal function which apparently is not affected by mercurials. In fact, potassium secretion is the only function considered to be distal in localization which is depressed by mercurials (26), but it has not been conclusively demonstrated that this too may not be proximal (3).

Duggan and Pitts (27) recently have concluded that in dogs mercurials act by depressing distal tubular reabsorption of electrolytes and water. This conclusion was based chiefly on the fact that despite massive doses of mercurials, the sodium excreted never exceeded $21 \%$ of that filtered, whereas, $67 \%$ to $87 \%$ of filtered sodium is generally considered to be reabsorbed proximally. They did agree, however, that if there were two proximal mechanisms for reabsorbing sodium, only one of which is mercury sensitive, their data could be as readily interpreted as indicating that mercurials act only on the proximal tubules. Mudge, Foulks and Gilman (23) have presented evidence that mercurial action in dogs during forced osmotic diuresis is probably exerted on proximal tubules, and noted that the percentage of filtered electrolyte appearing in the urine after mercurials may vary with the experimental conditions.

In this connection, the observations on patient A. C. are significant. In this acidotic subject, a hypertonic sodium chloride infusion served first to increase, and then to maintain the serum electrolyte concentration and the filtration rate after the mercurial. At the point of maximal diuresis, the water, sodium and chloride excreted were $32.9 \%$, $33.8 \%$ and $38.8 \%$ of the corresponding amounts filtered. Even if expressed in terms of the increases over the pre-mercurial excretions, and of the rate of sodium infusion $(3.4 \mathrm{mEq} . / \mathrm{min}$.), these values are far greater than could be attributed to distal tubule function alone (1). After the aminophyllin injection the filtration rate increased and a further rise occurred in the percentages of filtered electrolyte and water that were excreted.

Analysis of the changes in urinary sodium and chloride concentration in this patient provides still another approach to the question of renal site of action of mercurials. Prior to giving the mercurial, the hypertonic salt infusion had evoked the typical posterior pituitary antidiuretic hormone discharge, leading to decreased flow of urine with high electrolyte concentration (28). This posterior pituitary response was maintained throughout the study by continuing the hypertonic saline infusion. Under these circumstances, were no mercurial given, unpublished observations indicate that the urine flow would approximate 5 to $6 \mathrm{ml} . / \mathrm{min}$. with a sodium concentration of 170 to $190 \mathrm{mEq} . / 1$. As indicated above, mercurials have been reported to exert no effect on distal tubular facultative water reabsorption in dogs receiving very large doses of 
Pitressin $(3,25) .4$ Therefore, if mercurials act by depressing distal tubular electrolyte but not water reabsorption, leaving proximal activity unimpaired, diuresis in this case should have been associated with even higher urinary electrolyte concentrations.

Actually, after the mercurial, the urinary electrolyte concentrations fell significantly. If these drugs act by depressing proximal tubular reabsorption of electrolyte and water in man, without affecting distal water reabsorption at these high levels of endogenous antidiuretic hormone production, this decreased urine electrolyte concentration during diuresis could represent dilution of the otherwise concentrated urine by iso-osmotic filtrate which has escaped proximal reabsorption.

For example, the urine sodium concentration of $148 \mathrm{mEq}$./1. during the peak urine flow of 42 $\mathrm{ml} . / \mathrm{min}$. may be accounted for by the dilution of a small volume of hypertonic urine (sodium = $170-190 \mathrm{mEq} . / 1$.) with six to seven times its volume of iso-osmotic filtrate (sodium = 141-144 $\mathrm{mEq} . / 1$.). This additional filtrate, like that escaping proximal reabsorption during profuse osmotic diuresis, is little influenced by the activity of the distal tubules which, unaffected by the mercurial, are already reabsorbing water and electrolytes at virtually maximal rates (23).

Thus, the functional evidence in man, like the anatomical evidence, strongly suggests that much of the diuretic effect of mercurials is exerted proximally. Whether these drugs may also affect distal tubular function, remains to be established. Until the critical experiments have been devised to settle the latter point, final conclusions as to the site or nature of renal mechanisms for reabsorbing electrolytes, based on mercurialized men or animals, should be reserved.

\section{SUMMARY}

In an effort to determine whether mercurial diuretics affect distal tubular function in man, the effect of Thiomerin and Mercuzanthin on two active distal mechanisms-ammonia and titratable acidity production-was studied in patients subjected to ammonium chloride acidosis. The mer-

\footnotetext{
4 Whether mercurials inhibit distal tubular water reabsorption with high but physiological doses of Pitressin in man is being investigated in this laboratory.
}

curials had no effect on ammonia secretion. However, during the diuresis there was an increase in production of titratable acidity, probably resulting from greater load of phosphate and other buffers delivered to the distal tubule, secondary to mercurial inhibition of proximal tubular reabsorption. When the distal tubular load of phosphate was first increased by infusing a buffered sodium phosphate solution, the mercurials still produced an increase in titratable acidity production, which was again paralleled by augmented phosphate excretion.

To determine if an increased sodium load similarly might augment ammonia production, administration of the mercurial was preceded by rapid infusion of hypertonic saline in an acidotic subject. No significant change in ammonia or titratable acidity production was observed but at the height of diuresis, urinary water, sodium, and chloride excretions were $33 \%, 34 \%$ and $39 \%$ of the corresponding amounts filtered and there was a significant decrease in urinary electrolyte concentration.

The data are discussed in relation to site and mechanism of action of mercurial diuretics in man. It is concluded that much of the diuretic action of mercurials is exerted on the proximal tubule and that although these diuretics may also act on the distal tubules such effect on distal tubular function remains to be established.

\section{REFERENCES}

1. Wesson, L. G., Jr., Anslow, W. P., Jr., and Smith, $H$. W., The excretion of strong electrolytes. Bull. N. Y. Acad. Med., 1948, 24, 586.

2. Weston, R. E., Grossman, J., Escher, D. J. W., Mokotoff, R., and Leiter, L., Pathogenesis and treatment of salt and water retention in congestive failure. Med. Clin. N. America, 1950, 34, 615.

3. Pitts, R. F., and Sartorius, O. W., Mechanism of action and therapeutic use of diuretics. Pharmacol. Rev., 1950, 2, 161 ; also J. Pharm. \& Exper. Therap., 1950, 98, April (pt. 2).

4. Simonds, J. P., and Hepler, O. E., Experimental nephropathies: A method of producing controlled selective injury of renal units by means of chemical agents. Arch. Path., 1945, 39, 103.

5. Brun, C., Hilden, T., and Raaschou, F., On the effects of mersalyl (salyrgan) on the renal function. Acta pharmacol. \& toxicol., 1947, 3, 1.

6. Berliner, R. W., Kennedy, T. J., Jr., and Hilton, J. G., Salyrgan and renal tubular secretion of para- 
aminohippurate in the dog and man. Am. J. Physiol., 1948, 154, 537.

7. Weston, R. E., Grossman, J., Edelman, I. S., Escher, D. J. W., Leiter, L., and Hellman, L., Renal tubular action of diuretics. II. Effects of mercurial diuresis on glucose reabsorption. Federation Proc., 1949, 8, 164.

8. Talbott, J. H., Gout. Oxford Medical Publications, New York, 1943.

9. Blumgart, H. L., Gilligan, D. R., Levy, R. D., Brown, M. G., and Volk, M. C., Action of diuretics in normal persons. Arch. Int. Med., 1934, 54, 40.

10. Walker, A. M., Bott, D. A., Oliver, J., and MacDowell, M. C., The collection and analysis of fluid from single nephrons of the mammalian kidney. Am. J. Physiol., 1941, 134, 580.

11. Montgomery, H., and Pierce, J. A., The site of acidification of the urine within the renal tubule in amphibia. Am. J. Physiol., 1937, 118, 144.

12. Van Slyke, D. D., and Cullen, G. E., The determination of urea by the urease methods. J. Biol. Chem., 1916, 24, 117.

13. Henderson, L. J., and Palmer, W. W., On the several factors of acid excretion. J. Biol. Chem., 1914, 17, 305.

14. Fiske, C. H., and Subbarow, Y., The colorimetric determination of phosphorus. J. Biol. Chem., 1925, 66, 375.

15. Van Slyke, D. D., and Hiller, A., Application of Sendroy's iodometric chloride titration to proteincontaining fluids. J. Biol. Chem., 1947, 167, 107.

16. Clark, E. P., and Collip, J. B., A study of the Tisdall method for the determination of blood serum calcium with a suggested modification. J. Biol. Chem., $1925,63,461$.

17. Fiske, C. H., and Logan, M. H., Determination of calcium by alkimetric titration. II. The precipitation of calcium in the presence of magnesium, phos- phate, and sulfate, with applications to the analysis of urine. J. Biol. Chem., 1931, 93, 211.

18. Goldring, W., and Chasis, H., Hypertension and $\mathrm{Hy}-$ pertensive Disease. Commonwealth Fund, New York, 1944.

19. Pitts, R. F., and Alexander, R. S., The nature of the tubular mechanism for acidifying the urine. Am. J. Physiol., 1945, 144, 239.

20. Pitts, R. F., Lotspeich, W. D., Schiess, W. A., and Ayer, J. L., The renal regulation of acid-base balance in man. I. The nature of the mechanism for acidifying the urine. J. Clin. Invest., 1948, 27, 48.

21. Ryberg, C., The importance of sodium ions for the excretion of ammonia and hydrogen ions in the urine. Acta. physiol. Scandinav., 1948, 15, 161.

22. Mudge, G. H., Ames, A., III, Foulks, J., and Gilman, A., Effect of drugs on renal secretion of potassium in the dog. Am. J. Physiol., 1950, 161, 151.

23. Mudge, G. H., Foulks, J., and Gilman, A., Effect of urea diuresis on renal excretion of electrolytes. Am. J. Physiol., 1949, 158, 218.

24. Wesson, L. G., Jr., and Anslow, W. P., Jr., Excretion of sodium and water during osmotic diuresis in the dog. Am. J. Physiol., 1948, 153, 465.

25. Earle, D. P., Jr., and Berliner, R. W., Effect of 2,3dimercaptopropanol on diuresis. Am. J. Physiol., 1947, 151, 215.

26. Berliner, R. W., The tubular secretion of potassium and acid, in Tr. First Conf. on Renal Function, edited by Bradley, S. E. Josiah Macy, Jr. Foundation, N. Y., 1950.

27. Duggan, J. J., and Pitts, R. F., Studies on diuretics. I. The site of action of mercurial diuretics. J. Clin. Invest., 1950, 29, 365.

28. Hickey, R. C., and Hare, K., Renal excretion of chloride and water in diabetes insipidus. J. Clin. Invest., 1944, 23, 768. 